Original Research Paper

\title{
Knock Down of Erythrulose Kinase (eyk1) Leads to the Enhancement of Erythritol Production in Yarrowia lipolytica Mutant Strain YE4-2
}

\author{
${ }^{1,3+}$ Xinhe Zhao, ${ }^{2+}$ Tianlong Huang, ${ }^{2}$ Yaxin Zhang, ${ }^{1,4}$ Xiaojie Ren, ${ }^{1}$ Yuanda Song and ${ }^{2,5 *}$ Bei Guo \\ ${ }^{1}$ Colin Ratledge Center for Microbial Lipids, School of Agriculture Engineering and Food Science, \\ Shandong University of Technology, Zibo, Shandong, China \\ ${ }^{2}$ College of Bioscience and Resource Environment, Beijing University of Agriculture, Beijing, China \\ ${ }^{3}$ Chongqing Academy of Science and Technology, Chongqing, China \\ ${ }^{4}$ Baolingbao Biology Co. Ltd., Dezhou, Shandong, China \\ ${ }^{5}$ Key Laboratory of Urban Agriculture in North China, Ministry of Agriculture and Rural Affairs, P. R. China, Beijing, China
}

Article history

Received: 03-06-2020

Revised: 18-07-2020

Accepted: 23-07-2020

Corresponding Author:

Bei Guo

College of Bioscience and Resource Environment, Beijing University of Agriculture,

Beijing, China

Email: guobei2020@163.com co-first authors.
+ Contributed equally to this work and should be considered

\begin{abstract}
Erythritol is a nearly zero-calorie sweetener, which is in great demand in food and health care industry. Our previous work obtained a Yarrowia lipolytica mutant strain YE4-2 with high erythritol yield. However, its conversion rate of glucose needs further improvement. Erythrulose kinase (eykl) participates in the early stages of erythritol catabolism; the existence of eykl prevents the accumulation of erythritol. In this study, the genetic transformation system of $Y$. lipolytica YE4-2 was firstly established and the Cre/loxp homologous recombination knockout system was constructed. By using the Cre/loxp system, eykl gene was deleted. According to the PCR verification of eykl gene, it was preliminarily determined that one allele of eykl in this recombinant strain was knocked out. The recombination strain showed an average conversion rate of $48.51 \%$, which was $49.26 \%$ higher than that of YE4-2 and the erythritol productivity is increased by $62.26 \%$, which would be a significant improvement in the industrial scale.
\end{abstract}

Keywords: Erythritol, Yarrowia lipolytica, Genetic Transformation System, Cre/loxp, eyk1

\section{Introduction}

Erythritol is a substance widely existed in nature and it is a kind of sweetener with almost zero calories. The molecular energy value of erythritol is $1.67 \mathrm{~kJ} / \mathrm{g}$, which is the lowest among food-grade polyose sweeteners found so far, only about $1 / 10$ of that in sucrose (sucrose $16.72 \mathrm{~kJ} / \mathrm{g}$ ) (Bernt et al., 1996). According to literature reports, after the $24 \mathrm{~h}$ reaction time of once ingested erythritol in the body, about $80 \%$ of erythritol is excreted through urine and the remaining $20 \%$ is absorbed by the large intestine. The small amount of erythritol entering the large intestine is also difficult to be used by bacteria fermentation. Therefore, the actual energy value of erythritol is only $0.84 \mathrm{~kJ} / \mathrm{g}$, which is called "zero" calorific value sweetener (Kawanabe et al., 1992). In addition, erythritol also has the advantages of high tolerance in human body and small influence on blood insulin levels, so it is widely used in medicines and calorie-free food additive, bringing gospel to diabetes and obesity patients.

Erythritol is commonly generated from glucose via fermentation processes using osmophilic yeasts (Moon et al., 2010). It was found that the yeast used to produce erythritol included Torula sp. (Dou et al., 2013), Yarrowia lipolytica (Rymowicz et al., 2009), Pichia sp. (Lee et al., 2002), Candida sp. (Moon et al., 2010) and so on. The sugar tolerance, fermentation speed, efficiency and by-product ratio are important indexes for breeding high yield erythritol strains. Yarrowia lipolytica is able to utilize many carbon sources such as glycerol, glucose, fatty acids and alkanes (Papanikolaou et al., 2002). It could also use complex carbon sources, such as agricultural waste, corn steep liquor, to produce erythritol.

A strain Yarrowia lipolytica Y-22 (Pei et al., 2015) with high yield of erythritol and quite few byproducts of glycerol, ribitol was obtained in our lab by the flask fermentation of high-osmotic resistant yeasts from 
different sources. Its fermentation conversion rate can reach about $50 \%$ at different scale fermentation levels. Taking Y-22 as the starting strain and applying conventional NTG mutagenesis technique, a mutant strain YE4-2 with $20 \%$ higher erythritol yield was screened on the high-sugar mutagenesis medium after $1 \mathrm{~h}$ treatment at the NTG dose of $150 \mathrm{mg} / \mathrm{L}$ (Han et al., 2015). The mutant strain produced $192 \mathrm{~g} / \mathrm{L}$ erythritol by $4 \mathrm{~d}$ fermentation on $350 \mathrm{~m}^{3}$ fermentation tank, which was $20 \%$ higher than the original strain and the conversion rate was $56 \%$. However, the conversion rate is still far from the theoretical conversion rate. Therefore, our work attempts to modify the erythritol metabolic pathway on molecular level, so as to further increase the erythritol accumulation. The metabolic pathways of Yarrowia lipolytica on glucose or glycerol are shown in Fig. 1. When erythritol is synthesized from glycerol, the latter is initially catalyzed by glycerol kinase and then glycerdehydrogenase to produce Dihydroxyacetone Phosphate (DHAP). DHAP enters into the pentose phosphate pathway and is converted into erythrose-4-phosphate by a Transketolase (TK). While when glucose is applied as carbon source, it enters the glycolysis pathway under the action of Hexokinase (HK) and the intermediate glucose 6phosphate enters the pentose phosphate pathway (HMP) under the action of Glucose-6-Phosphate Dehydrogenase
(G6PD). The latter is converted into erythrose-4phosphate by a series of Transketolase (TKL) and Transaldolase (TAL). Then the erythrose-4-phosphate from both the glycerol and glucose is dephosphorylated by an Erythrose-4P Phosphatase (E4PP) to erythrose and then reduced to erythritol by an Erythrose Reductase (ER). However, erythritol is not the terminal product of the metabolism; $Y$. lipolytica can also use it as carbon source. Vandermies et al. (2017) reported that the gene eykl encodes Erythrulose Kinase (EK), which is involved in the early stage of erythritol catabolism (shown in the red dotted frame). It can phosphorylate erythriol's direct downstream product erythritose and generate erythritose phosphate. The latter can continue to produce methyl aldehyde (formaldenhyde) and Dihydroxyacetone Phosphate (DHAP), which goes to glycolysis or TCA pathway. Thus, the catabolism of erythritol causes a certain negative effect on the accumulation of erythritol. Our hypothesis is the knocking down of the erythrulose kinase gene $(e y k l)$ could eliminate the erythritol splitflow, therefore increase its accumulation. In this study, the genetic transformation system of Yarrowia lipolytica was established and on this basis, the Cre/loxp recombinant system was used to knockout eykl gene of Yarrowia lipolytica, thereby inhibiting the catabolism of erythritol and improving the yield.

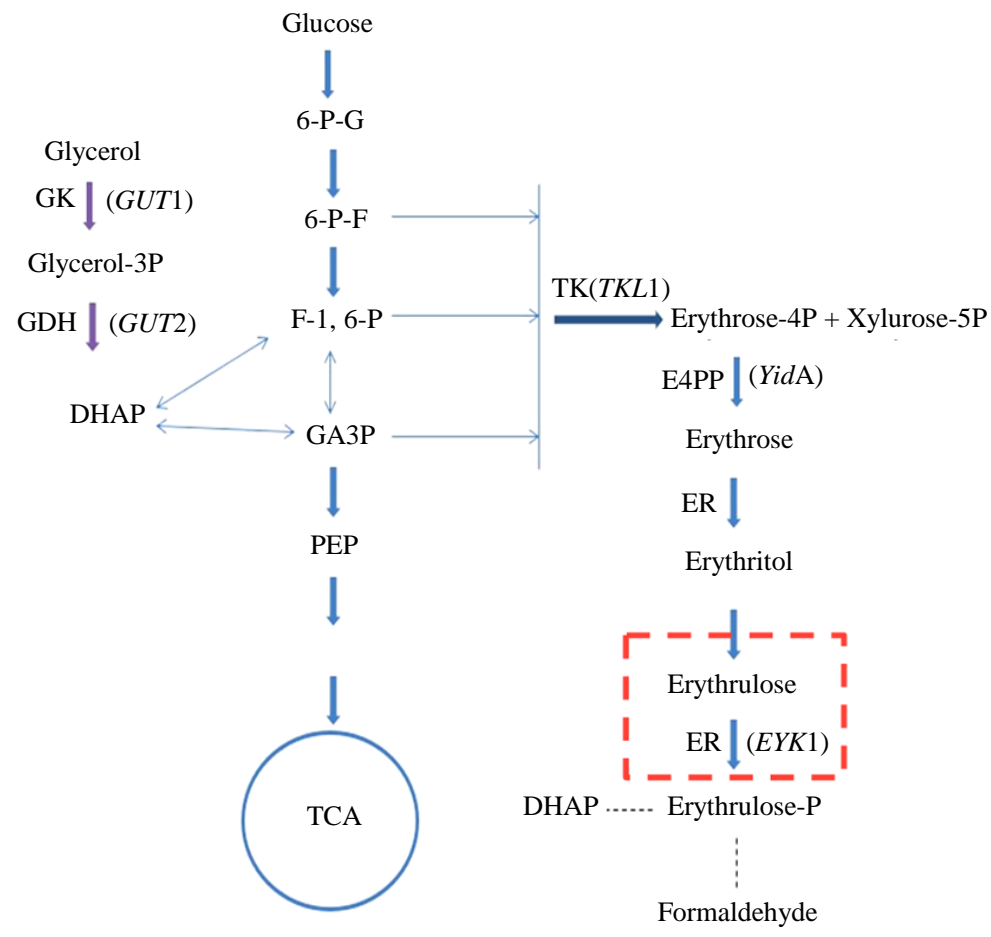

Fig. 1: Metabolic of erythritol in yeast; (GK: Glycerol Kinase; GDH: Glycerdehydrogenase; DHAP: Dihydroxyacetone Phosphate; 6-P-G: Glucose 6-Phosphate; 6-P-F: Fructose-6-Phosphate; F-1, 6-P: Fructose-1, 6-Diphosphate; GA3P: 3Phosphoglyceraldehyde; PEP: Phosphoenolpyruvate; PA: Pyruvic Acid; TCA: Tricarboxylic Acid Cycle; TK: Transketolase; E4PP: Erythrose-4P Phosphatase; ER: Erythrose Reductase; EK: Erythrulose Kinase) 


\section{Material and Methods}

\section{Strains and Culture Conditions}

Y. lipolytica Y-22 and Y. lipolytica YE4-2 were preserved in our lab. The mutant strain $Y$. lipolytica YE4-2 used in this study were derived from the wildtype $Y$. lipolytica Y-22 (Pei et al., 2015). The $Y$. lipolytica strains were grown in Yeast extract Peptone Dextrose (YPD) medium containing $10 \mathrm{~g}$ yeast extract, $20 \mathrm{~g}$ tryptone and $20 \mathrm{~g}$ glucose in one liter Milli-Q water and for solid media, $20 \mathrm{~g} / \mathrm{L}$ agar was added. Shake-flask cultures were performed in triplicate in a rotary shaker (DLHR-Q200, HDL APPARATUS) at $30^{\circ} \mathrm{C}$ and 200 rpm. After $72 \mathrm{~h}$ of preculturing in $35 \mathrm{~mL}$ of YPD liquid medium, cells were collected by centrifuging under 5600 $\mathrm{g}$ at $4{ }^{\circ} \mathrm{C}$ (centrifuge, 5804R, Eppendorf) and were transferred to a 250 mL-flask containing $35 \mathrm{~mL}$ of fermentation medium $\left(25 \%\right.$ glucose, $0.5 \% \mathrm{NH}_{4} \mathrm{CIT}$, $0.5 \%$ yeast extract, $0.025 \% \quad \mathrm{MgSO}_{4}, 0.025 \% \quad \mathrm{KH}_{2} \mathrm{PO}_{4}$ and $0.005 \% \mathrm{CuSO}_{4}$ ) for fermentation at $30^{\circ} \mathrm{C}$ and 200 $\mathrm{rpm}$. Then the $96 \mathrm{~h}$ of fermentation cultures were collected for further analysis.

\section{Screen of Antibody Resistant for Y. lipolytica}

$Y$. lipolytica cells were collected by centrifugation of liquid culture at $4{ }^{\circ} \mathrm{C}, 5600 \mathrm{~g}$ for $5 \mathrm{~min}$, the sediment were diluted to $1 \times 10^{6}$ cells $/ \mathrm{ml}$ after washing with sterile physiological saline. $100 \mu \mathrm{L}\left(1 \times 10^{5}\right.$ cells $)$ of the dilution was coated to YPD plates containing different antibiotics in triplicate. The concentration gradient of antibiotics were set to $0,400,600,700,800,1000 \mathrm{mg} / \mathrm{L}$ for geneticin G418 (Shenggong, China) and zeocin (Invitrogen, USA); 0, 20, 60, 150, 200, $300 \mathrm{mg} / \mathrm{L}$ for phleomycin (Invitrogen, USA) and 0, 200, 400, 600, 700, $800,1000 \mathrm{mg} / \mathrm{L}$ for hygromycin B (Invitrogen, USA). The coated plates were placed in the incubator at $30^{\circ} \mathrm{C}$ for 7 days and the inhibitory effects of different concentrations of antibiotics on the strains were observed.

\section{Selection of Electrical Shock Conditions for $Y$. lipolytica}

The expression vector pPICZ $\alpha$ A carrying zeocin/ phleomycin resistance gene was digested with restriction endonuclease Sac I to prepare a linearized plasmid. Different plasmid concentrations, shocking voltages and shocking time on the conversion efficiency to $Y$. lipolytica were tested. The linearized plasmid $\mathrm{pPICZ} \alpha \mathrm{A}(5,6,7,8$, 9, $10 \mathrm{ug}$ ) was added to $80 \mathrm{uL}$ Y. lipolytica YE4-2 competent cells for electroporation, the conversion voltage was $1500 \mathrm{~V}, 1800 \mathrm{~V}, 2000 \mathrm{~V}, 2200 \mathrm{~V}$ and the shocking time was 4, 5, $6 \mathrm{~ms}$. After the electric shock, $1 \mathrm{~mL}$ of precooled sorbitol was immediately added to the system and cells were placed at a $30^{\circ} \mathrm{C}$ shaker at $100 \mathrm{rpm} / \mathrm{min}$ for $1 \mathrm{~h}$. Then $200 \mathrm{uL}$ of the rejuvenated cells were coated to the YPD solid plate containing $300 \mathrm{mg} / \mathrm{L}$ of phleomycin.
After incubation two days at $30^{\circ} \mathrm{C}$, the transformants number was recorded and transformants were selected for PCR positive identification to determine transformation efficiency. The primers zeo-F/R used in PCR verification are shown in the appendix. Construction of selective vector for $Y$. lipolytica.

The sequence of pPICZ $\alpha \mathrm{A}$ was obtained from the NCBI website, primers were designed (see appendix for primers) according to the sequence information. The zeocin resistance gene expression cassette pTEFpEM7-zeocin-TT (ppz) was amplified by PCR and ligated to the pCloneEZ-TOPO vector (Taihe Biotechnology, Beijing, China). The new plasmid was named as pCloneEZ::ppz and was transformed to E. coli DH5 $\alpha$. Positive transformants were screened on zeocinresistant plates. Then pCloneEZ::ppz was extracted from positive transformants and digested with $\mathrm{Xba} \mathrm{I}$ and $\mathrm{Bgl}$ II. The $p p z$ fragment was cloned into the same enzyme digested (Xba I and Bgl) pUG6 vector to obtain ppz selectable plasmid pUG::ppz.

The hpt II gene in the pCAMBIA1300 plasmid was cloned by the same method and digested with Nco I and Cla I and then cloned into pUG6 vector to obtain $h p t$ selectable plasmid pUG::hpt. All restriction enzymes were purchased from FastDigest Thermo Scientific ${ }^{\text {TM }}$ (USA). The correctness of the resulting constructs was verified by DNA sequencing.

\section{Construction of eykl Deleted Mutant based on Crelloxp Recombination System}

The eykl Disruption Cassettes (DC) were constructed according to a cloning-free strategy derived from Cre-lox method (Fickers et al., 2003). The mechanism of Cre/loxp system can be simply divided into the following steps (Vandermies et al., 2017). (1) Constructing a vector carrying two palindromic structures, loxp, between which, a resistance screening marker gene can be attached; (2) a primer carrying a 40-80 bp target gene flank sequence and loxp sequence were applied to amplify the knockout component. (3) The linearized knockout module was transformed into a recipient cell by electroporation transformation and integrated into the genome by homologous recombination to obtain a transformant. (4) Linearized plasmid carrying the Cre recombinase was transferred to the transformant obtained in the previous step and then genes between loxp sites were associated, recombined and disintegrated under the effect of Cre (Dolinski et al., 1997; Hirschman et al., 2006). Since the two loxp sites are asymmetric and directional, it thus mediated three different recombination reactions (Vandermies et al., 2017): (1) when the direction is opposite, the segment between the two sites is inverted; (2) when the direction is syntropy, the segment between the two sites is deleted; (3) when the two sites are on different molecules, the translocation would occur, as Fig. 2. 


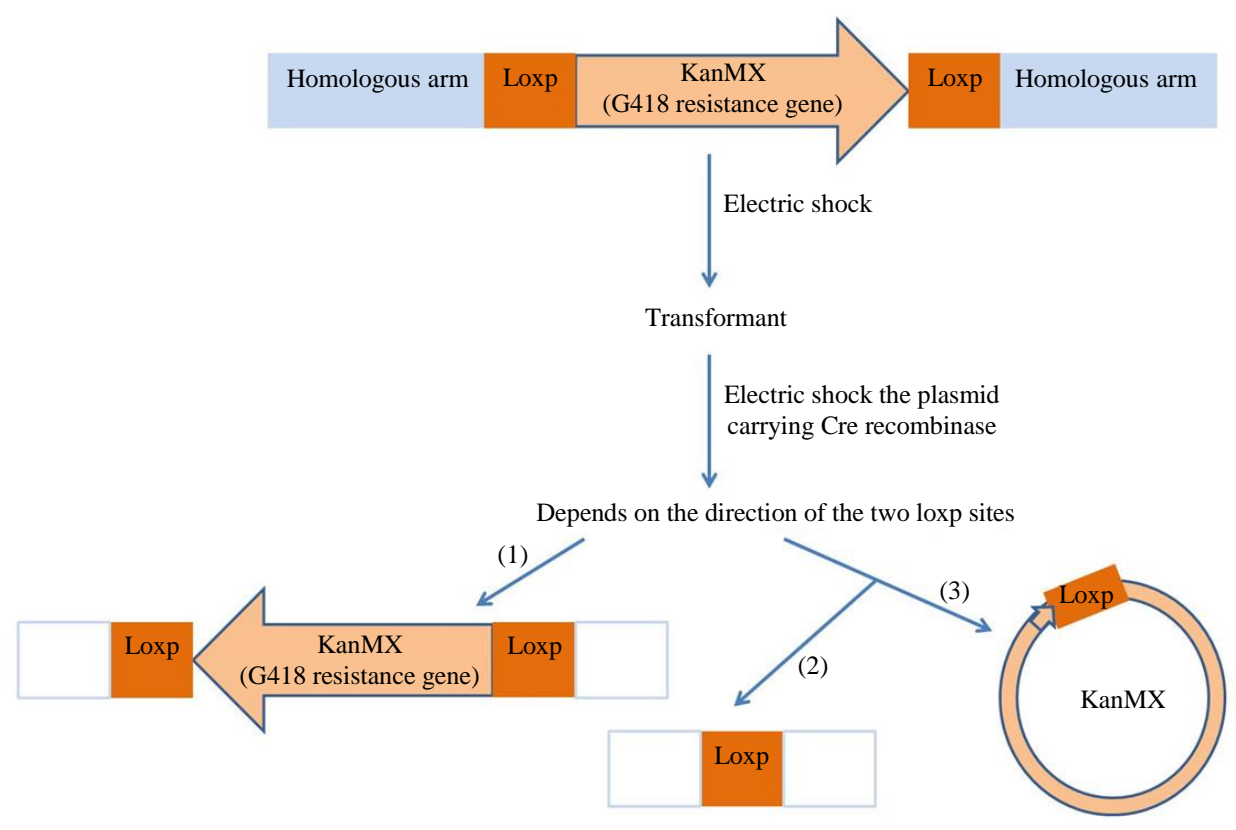

Fig. 2: The mechanism of Cre/loxp system

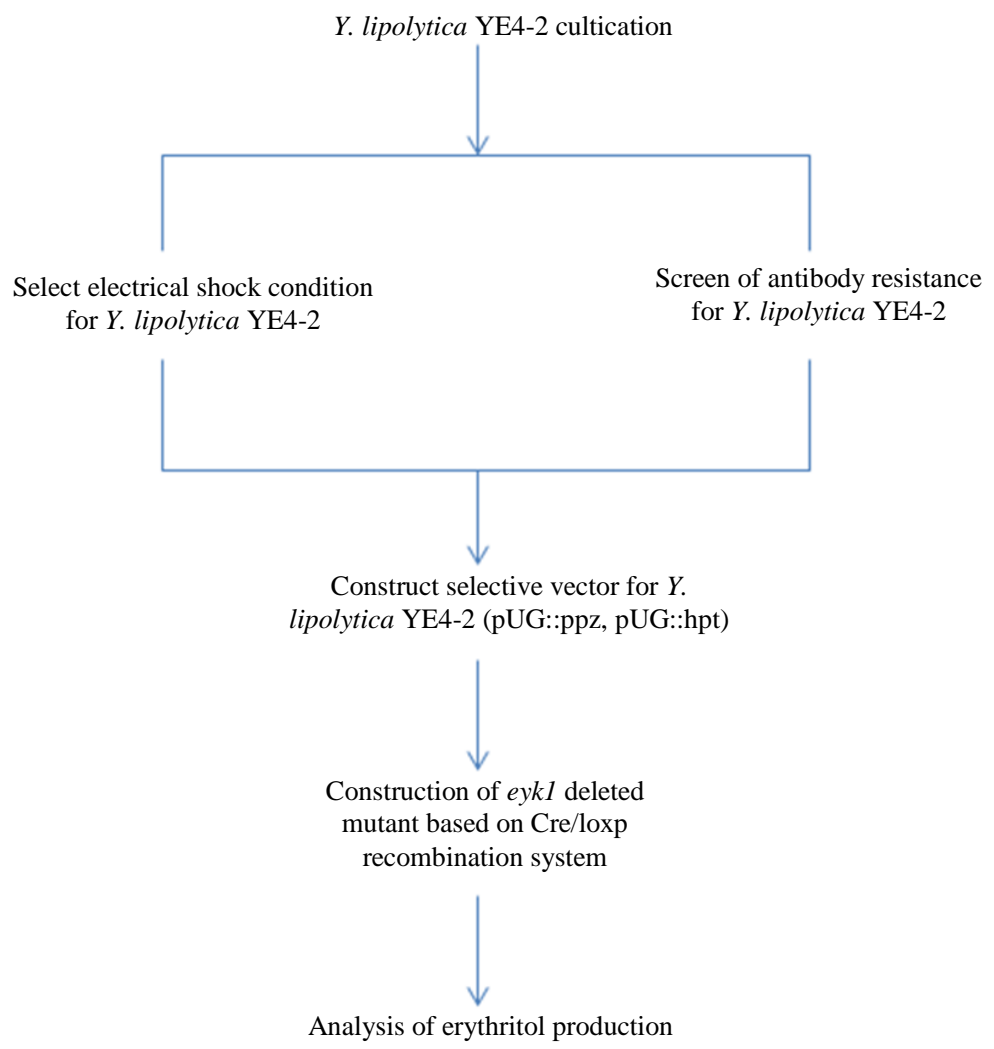

Fig. 3: Overall process map in this research

In this study, the primer EL-F/R was designed based on the $Y$. lipolytica eykl gene and the pUG6::hpt II plasmid loxP-hpt II -loxP. The 5' ends of EL-F and EL-R have $60 \mathrm{bp}$ homologous bases with the $Y$. lipolytica eykl gene flankings, respectively. The 3 ' ends of EL-F and EL-R have 19 bases homologous with the loxP-hpt II- 
loxP flanking sequences of plasmid pUG6. The pUG6hpt II vector was used as the template and the knockout component containing eykl up- -loxp-hpt II-loxp-eykl down was amplified using EL-F/R primers. Primers sequences are shown in the appendix.

Then the knockout module (5 ug) was mixed with 80 $\mathrm{uL} Y$. lipolytica YE4-2 competent cells and electroshocked at $2000 \mathrm{~V}$ for $6 \mathrm{~ms}$. $1 \mathrm{~mL}$ of pre-cooled sorbitol was quickly added and shaken slowly for $2 \mathrm{~h}$ at $30^{\circ} \mathrm{C}$. Then cells were applied to the YPD plate containing $800 \mathrm{mg} / \mathrm{L}$ hygromycin $\mathrm{B}$ and cultured at $30^{\circ} \mathrm{C}$ for 2 days. The transformed yeast was verified by PCR to identify whether the sequence of interest was correctly knocked out or integrated.

\section{Quantifying Biomass, Glucose Concentration and Erythritol Concentration}

Biomass was determined gravimetrically after the cells had been washed and dried at $105^{\circ} \mathrm{C}$ for $24 \mathrm{~h}$ $\left(\mathrm{W}_{\text {dry biomass }}=\mathrm{W}_{\text {clean tube with dry cells }}-\mathrm{W}_{\text {the clean tube }}\right)$. Biomass yield was defined as the dry weight of biomass (W) per liter fermentation broth $(\mathrm{g} / \mathrm{L})$. Glucose and erythritol concentrations were determined using an HPLC (Agilent 1200 series; Agilent Technologies) equipped with a refractive index detector and an Aminex HPX-87H ion exclusion column $(300 \times 7.8 \mathrm{~mm}$; Bio-Rad). Elution was performed using $15 \mathrm{mM}$ trifluoroacetic acid as the mobile phase at a flow rate of $0.5 \mathrm{~mL} / \mathrm{min}$ and a temperature of $65^{\circ} \mathrm{C}$ (Jovanović et al., 2014). Their concentrations $(\mathrm{g} / \mathrm{L})$ were determined according to the standard curves established in this study. Glucose utilization rate $=($ glucose concentration before fermentation - glucose concentration after the fermentation)/glucose concentration before fermentation $\times 100 \%$. Product yield $(\mathrm{g} / \mathrm{L})=$ erythritol concentration after fermentation- erythritol concentration before fermentation. Erythritol productivity $(\mathrm{g} / \mathrm{L} / \mathrm{h})=$ product $y$ ield/fermentation time . Conversion rate $(\%)=$ product yield $(\mathrm{g} / \mathrm{L}) / \mathrm{glucose}$ utilized (g/L) $\times 100 \%$ (Germec et al., 2019).

Finally, an overall process map was drawn to clearly show the research steps (Fig. 3).

\section{Results and Discussion}

\section{Screen of Antibody Resistant of Y. lipolytica}

The most commonly used resistance screening markers for genetic engineering of industrial scale applied yeast are Geneticin (G418), zeocin, phleomycin, hygromycin B etc., (Fu, 2013; Vickers et al., 2013; Amelina et al., 2016). In order to achieve genetic modification of $Y$. lipolytica YE4-2, it is necessary to find a proper resistance screening marker. In this experiment, four commonly used yeast screening antibiotics were selected for the resistance screening test of the starting strain $Y$. lipolytica Y-22 and the mutant strain $Y$. lipolytica YE4-2. Since the same microorganism has a certain tolerance range for different antibiotics. This range is inconsistent for different antibiotics; in addition, different microorganisms have different tolerances for the same antibiotic. Therefore, we first searched the literature to find the range of sensitivity of $Y$. lipolytica to different antibiotics and then through gradient experiments, we finally determined its reasonable use concentration, so as to achieve the purpose of screening strains. According to the method in $2.2,1 \times 10^{5}$ cell solutions were applied to YPD plates with different type and concentration of antibodies.

The growth on geneticin G418 was observed as shown in Table 1. It shows that even at a high concentration $(1000 \mathrm{mg} / \mathrm{L})$ of geneticin G418, $Y$. lipolytica can still grow and the inhibitory effect is not obvious. The growth of the cells on YPD plates with different concentrations of zeocin is shown in Tab.2. When zeocin reached $400 \mathrm{mg} / \mathrm{L}$, the yeast was inhibited from growing within $48 \mathrm{~h}$, however colonies were observed after $48 \mathrm{~h}$. When the concentration reached 800 $\mathrm{mg} / \mathrm{L}$, the inhibitory effect could be extended to $72 \mathrm{~h}$. When zeocin concentration was $1000 \mathrm{mg} / \mathrm{L}$, only a few single colonies appeared after $96 \mathrm{~h}$.

It was reported that phleomycin, which is the same family as zeocin and can also be degraded by the resistance gene shble, has a good inhibitory effect on zeocin-insensitive yeast (Chen et al., 2008; Falciatore et al., 1999). Cell dilution was applied to YPD plates with different concentrations of phleomycin according to the method of 2.2. After incubation at $30^{\circ} \mathrm{C}$ for a period of time, the growth was observed as shown in Table 3. When the concentration of phleomycin reaches 300 $\mathrm{mg} / \mathrm{L}$, it has obvious inhibitory effect on $Y$. lipolytica. However, the drawback is that phleomycin is relatively expensive, $1 \mathrm{~mL}$ of $20 \mathrm{mg} / \mathrm{ml}$ phleomycin requires 700 RMB, thus the cost will be high when applying phleomycin in such a high concentration.

The growth of the cells on YPD plates with different concentrations of hygromycin B is shown in Table 4. It can be seen that when hygromycin B reaches $200 \mathrm{mg} / \mathrm{L}$ or more $(200-400 \mathrm{mg} / \mathrm{L})$, it has an inhibitory effect on $Y$. lipolytica. However, after the incubation time increased to $72 \mathrm{~h}$, colonies appear. When the antibiotic concentration was increased to $800 \mathrm{mg} / \mathrm{L}, Y$. lipolytica YE4-2 could not grow, while for the starting strain Y-22, there are sporadic colonies growing after $120 \mathrm{~h}$ of culture. According to the characteristics of antibiotics, it is considered that the antibiotics may gradually break down. Therefore, hygromycin B can be used as a screening resistance for $Y$. lipolytica and the screening concentration is set at $800 \mathrm{mg} / \mathrm{L}$. 
Table 1: G418 resistant screening

Culture time and growth condition

\begin{tabular}{|c|c|c|c|c|c|}
\hline No. & Antibody & Final concentration & $24 \mathrm{~h}$ & $48 \mathrm{~h}$ & $72 \mathrm{~h}$ \\
\hline (1) & G418 & $0 \mathrm{mg} / \mathrm{L}$ & +++ & ++++ & +++++ \\
\hline (2) & G418 & $400 \mathrm{mg} / \mathrm{L}$ & + & ++ & +++ \\
\hline (3) & G418 & $600 \mathrm{mg} / \mathrm{L}$ & + & ++ & +++ \\
\hline (4) & G418 & $800 \mathrm{mg} / \mathrm{L}$ & + & ++ & ++ \\
\hline (5) & G418 & $1000 \mathrm{mg} / \mathrm{L}$ & + & ++ & ++ \\
\hline
\end{tabular}

(Note: + Small colonies and low density; ++ Medium size and dense colonies; +++ Overgrown the entire plate, small colonies; ++++ Overgrown the entire plate, medium colonies; +++++ Overgrown the entire plate, large colonies; None: no clonies grow. The same note for the Tables 2, 3 and 4)

Table 2: Zeocin resistant screening

\begin{tabular}{|c|c|c|c|c|c|c|}
\hline \multirow[b]{2}{*}{ No. } & \multirow[b]{2}{*}{ Antibody } & \multirow[b]{2}{*}{ Final concentration } & \multicolumn{4}{|c|}{ Culture time and growth condition } \\
\hline & & & $24 \mathrm{~h}$ & $48 \mathrm{~h}$ & $72 \mathrm{~h}$ & $96 \mathrm{~h}$ \\
\hline (1) & Zeocin & $0 \mathrm{mg} / \mathrm{L}$ & ++ & +++ & ++++ & +++++ \\
\hline (2) & Zeocin & $400 \mathrm{mg} / \mathrm{L}$ & None & + & ++ & ++++ \\
\hline (3) & Zeocin & $600 \mathrm{mg} / \mathrm{L}$ & None & + & ++ & +++ \\
\hline (4) & Zeocin & $800 \mathrm{mg} / \mathrm{L}$ & None & None & + & ++ \\
\hline (5) & Zeocin & $1000 \mathrm{mg} / \mathrm{L}$ & None & None & None & + \\
\hline
\end{tabular}

(Note: see Table 1)

Table 3: Phleomycin resistant screening

\begin{tabular}{|c|c|c|c|c|c|}
\hline \multirow[b]{2}{*}{ No. } & \multirow[b]{2}{*}{ Antibody } & \multirow[b]{2}{*}{ Final concentration } & \multicolumn{3}{|c|}{ Culture time and growth condition } \\
\hline & & & $24 \mathrm{~h}$ & $48 \mathrm{~h}$ & $72 \mathrm{~h}$ \\
\hline (1) & Phleomycin & $0 \mathrm{mg} / \mathrm{L}$ & +++ & ++++ & +++++ \\
\hline (2) & Phleomycin & $20 \mathrm{mg} / \mathrm{L}$ & + & ++ & +++ \\
\hline (3) & Phleomycin & $60 \mathrm{mg} / \mathrm{L}$ & + & ++ & +++ \\
\hline (4) & Phleomycin & $150 \mathrm{mg} / \mathrm{L}$ & None & + & ++ \\
\hline (5) & Phleomycin & $200 \mathrm{mg} / \mathrm{L}$ & None & None & + \\
\hline (6) & Phleomycin & $300 \mathrm{mg} / \mathrm{L}$ & None & None & None \\
\hline
\end{tabular}

(Note: see Table 1)

Table 4: Hygromycin B resistant screening

\begin{tabular}{|c|c|c|c|c|c|c|}
\hline \multirow[b]{2}{*}{ Strain } & \multirow{2}{*}{$\begin{array}{l}\text { Hygromycin B } \\
\text { final concentration }\end{array}$} & \multicolumn{4}{|c|}{ Culture time and growth condition } & \multirow[b]{2}{*}{$120 \mathrm{~h}$} \\
\hline & & $24 \mathrm{~h}$ & $48 \mathrm{~h}$ & $72 \mathrm{~h}$ & $96 \mathrm{~h}$ & \\
\hline $\mathrm{Y}-22$ & $0 \mathrm{mg} / \mathrm{L}$ & + & ++ & +++ & +++ & ++++ \\
\hline YE4-2 & & + & ++ & +++ & +++ & ++++ \\
\hline Y-22 & $200 \mathrm{mg} / \mathrm{L}$ & None & None & + & + & +++ \\
\hline YE4-2 & & None & None & + & + & ++ \\
\hline Y-22 & $400 \mathrm{mg} / \mathrm{L}$ & None & None & + & + & +++ \\
\hline YE4-2 & & None & None & + & + & ++ \\
\hline Y-22 & $600 \mathrm{mg} / \mathrm{L}$ & None & None & None & + & +++ \\
\hline YE4-2 & & None & None & None & + & ++ \\
\hline Y-22 & $700 \mathrm{mg} / \mathrm{L}$ & None & None & None & + & +++ \\
\hline YE4-2 & & None & None & None & +- & ++ \\
\hline Y-22 & $800 \mathrm{mg} / \mathrm{L}$ & None & None & None & None & +- \\
\hline YE4-2 & & None & None & None & None & None \\
\hline$Y-22$ & $1000 \mathrm{mg} / \mathrm{L}$ & None & None & None & None & None \\
\hline YE4-2 & & None & None & None & None & None \\
\hline
\end{tabular}

(Note: see Table 1)

In summary, even under high concentration of geneticin G418, the inhibition effect to $Y$. lipolytica is not obvious; in the presence of zeocin, when the antibiotic concentration reaches $1000 \mathrm{mg} / \mathrm{L}$, it has a good inhibitory effect within $96 \mathrm{~h}$; in the presence of phleomycin, when the antibiotic concentration reaches 
$300 \mathrm{mg} / \mathrm{L}$, it has a good inhibitory effect within $72 \mathrm{~h}$; Zeocin and phleomycin are the same classes of antibiotics that can be inhibited by the same resistance gene (shble). Therefore, $1000 \mathrm{mg} / \mathrm{L}$ zeocin and 300 $\mathrm{mg} / \mathrm{L}$ phleomycin could be selected as screening antibiotic and the effective screening time was $72 \mathrm{~h}$. Hygromycin B resistance has an obvious inhibitory effect when the concentration is above $800 \mathrm{mg} / \mathrm{L}$ and has a good screening effect within $120 \mathrm{~h}$. Therefore, hygromycin B was selected as a screening antibiotic with a screening concentration of $800 \mathrm{mg} / \mathrm{L}$ and an effective screening time of $96 \mathrm{~h}$.

\section{Optimization of Electric Shock Conditions of $Y$. lipolytica}

$Y$. lipolytica is an unconventional high-osmotic resistant yeast, its cell wall is relatively thick. However, most of the electroporation methods for $Y$. lipolytica directly apply those used in common yeasts such as Pichia pastoris and Saccharomyces cerevisiae which are not so efficient (Fraczek et al., 2018). In this experiment, the electroporation transformation conditions of $Y$. lipolytica were explored to find better transformation parameters.

Here, different concentrations of pPICZ $\alpha \mathrm{A}$ (carrying zeocin/phleomycin resistance gene shble) were transformed under different shock voltage and time. After the transformation, $Y$. lipolytica was applied to the YPD plate containing $300 \mathrm{mg} / \mathrm{L}$ of phleomycin and cultured at $30^{\circ} \mathrm{C}$ for two days. The number of single colonies was recorded and the transformants were subjected to PCR for verification. Results show that the most monoclonal can be obtained when 5 ug plasmids $180 \mathrm{uL}$ competent cell were transformed under $2000 \mathrm{~V}$ for $6 \mathrm{~ms}$ and the transformants grow well; The transformants under this electric shock condition were identified by PCR and the positive conversion rate was $80 \%$. Therefore, plasmid $5 \mathrm{ug} / 80 \mathrm{uL}$, at $2000 \mathrm{~V}$, for $6 \mathrm{~ms}$ were selected as the conditions for electrotransformation. The electrotransformation method uses transient highvoltage electric pulses to create temporary pores on the cell surface, which can form small pores on the surface of the cell membrane (Saito et al., 2006). At the same time, due to the electric shock action, the cell membrane is fused and finally a large pore is formed on the cell membrane for easy DNA entry. But there are many factors that affect the efficiency of electric conversion, such as electric shock voltage, pulse time, DNA content and so on. The results show that the electrical conversion efficiency is proportional to the content of exogenous DNA within a certain range, but excessive addition of exogenous DNA will cause the conversion efficiency to decrease. This result is basically consistent with literature reports (Kimoto et al.,
2003). In addition, under high shock voltage, the cell wall and plasma membrane can be instantaneously broken, while under low field strength, the accumulated charge must reach a certain strength before it can act on the plasma membrane to form pores. Therefore, the combination of proper pulse electric shock voltage and pulse time can improve the efficiency of electric conversion (Kimoto et al., 1997).

\section{Construction of the Y. lipolytica Selective Vector}

The pUG6 vector contains a Cre-loxp recombination system and is commonly used for yeast gene knockout (Twaruschek et al., 2018; Wei et al., 2018). Since $Y$. lipolytica is sensitive to zeocin and hygromycin B, the pUG6 vector was first modified to achieve zeocin and hygromycin B resistance, respectively. The zeocin resistance gene was obtained by PCR from the plasmid pPICZ $\alpha \mathrm{A}$ and the hygromycin B resistance gene was obtained by PCR from the plasmid pCAMBIA1300. The resistance gene fragment and the pUG6 were cleaved and ligated according to the method 2.4 to construct the $Y$. lipolytica selective vector pUG6::ppz and pUG6::hpt II respectively (Fig. 4).

The results of transformation of pUG6::ppz to E.coli are shown in Fig. 5a. The migration rates of extracted plasmids No. 1-12 were slower than that of pUG6 (No. 13), which proved that the plasmids of 1-12 were all recombinant plasmids. The results of double enzyme digestion showed that the $4004 \mathrm{bp}$ vector band (PUG6) and the $1174 \mathrm{bp} \mathrm{ppz}$ fragment could be successfully cleaved from the recombinant plasmid (Fig. 5b). Further plasmid sequencing also verified this (data not shown). Therefore, it was confirmed that the $p p z$ fragment was successfully constructed on pUG6. At the same time, the E. coli transformants of the pUG6::ppz plasmid can be grown on a plate containing $50 \mathrm{mg} / \mathrm{L}$ zeocin, indicating that the pUG6::ppz vector has been successfully constructed. Thus it could be used for the next gene knockout assay.

For the transformant of pUG6:: hpt II, the hygromycin B gene were verified by PCR (Fig. 6a) and restriction enzyme digestion (Fig. 6b). From PCR verification, plasmids $3,9,10$ and 11 were identified as positive transformant and enzyme digestion further proved it contains a 1041 bp $h p t$ II and 3890 bp linear vector. The results showed that hpt II was successfully constructed on the pUG6 vector.

\section{Disruption of eykl Gene in Y. lipolytica YE4-2}

According to the method in 2.5, the knockdown component eyk ${ }^{\text {up }}$-loxp-hpt II-loxp-eyk ${ }^{\text {down }}$ (2684 bp) was amplified using the recombinant plasmid pUG6::hpt II as template and EL-F/R (carrying eykl flank sequences and loxp sequences) as primers. The liner 
knockdown component was transformed into $Y$. lipolytica YE4-2 and after two days of culturing, the transformants were collected to screen eykl disruption strains. Hygromycin B resistance gene based $h p t-\mathrm{F} / \mathrm{R}$ was applied as primer and the results are shown in Fig. 7a. From transformants 1, 3 and 4, a band (1041 bp) equal in size to the positive control strip was cloned. It was initially determined that the hygromycin B resistance gene was successfully transferred into yeast genome DNA.
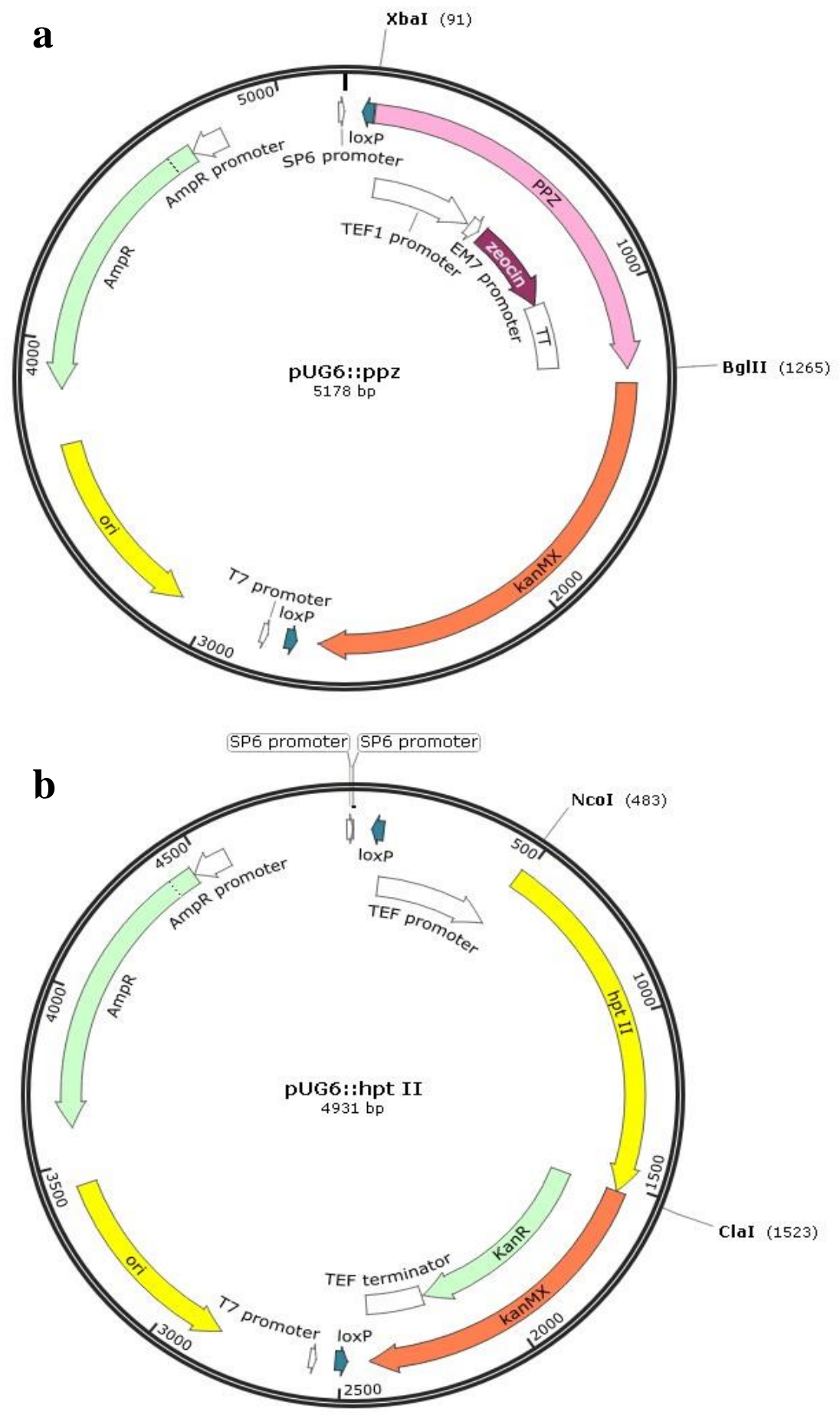

Fig. 4: Plasmid map of pUG::ppz and pUG::hptII. a: Plasmid map of pUG::ppz; b : Plasmid map of pUG::hptII 

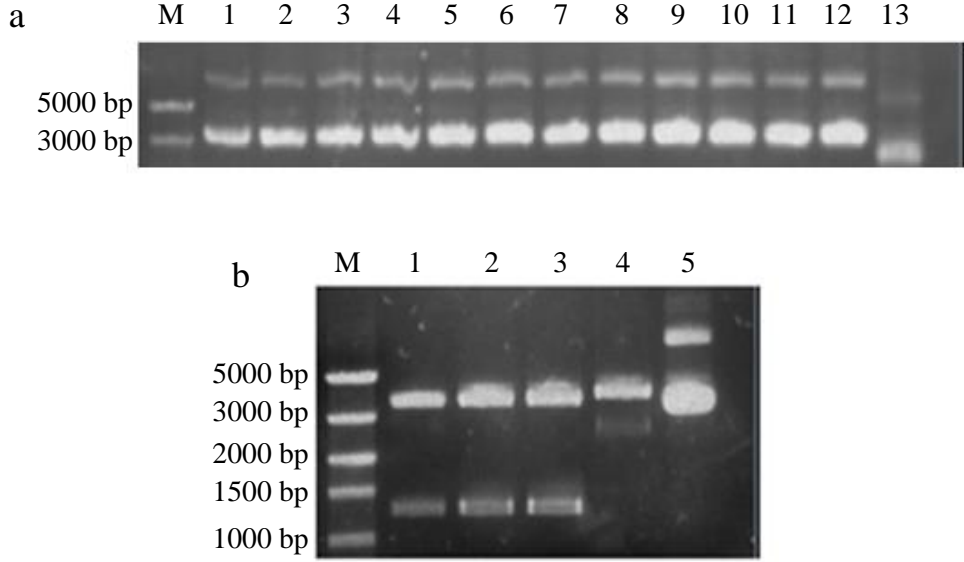

Fig. 5: Transformatnt verification of plasmid pUG::ppz. a. PCR identification of pUG::ppz ( M: 5000bp DNA maker; 1-12: PCR result of the transformants; 13: PCR result of pUG6); b. Double enzyme digestion identification of pUG::ppz (M: 5000bp DNA maker; 1-3: Xba I/Bgl II digestion of plasmid pUG::ppz; 4: Plasmid of pUG6; 5: Plasmid of pUG6::ppz)
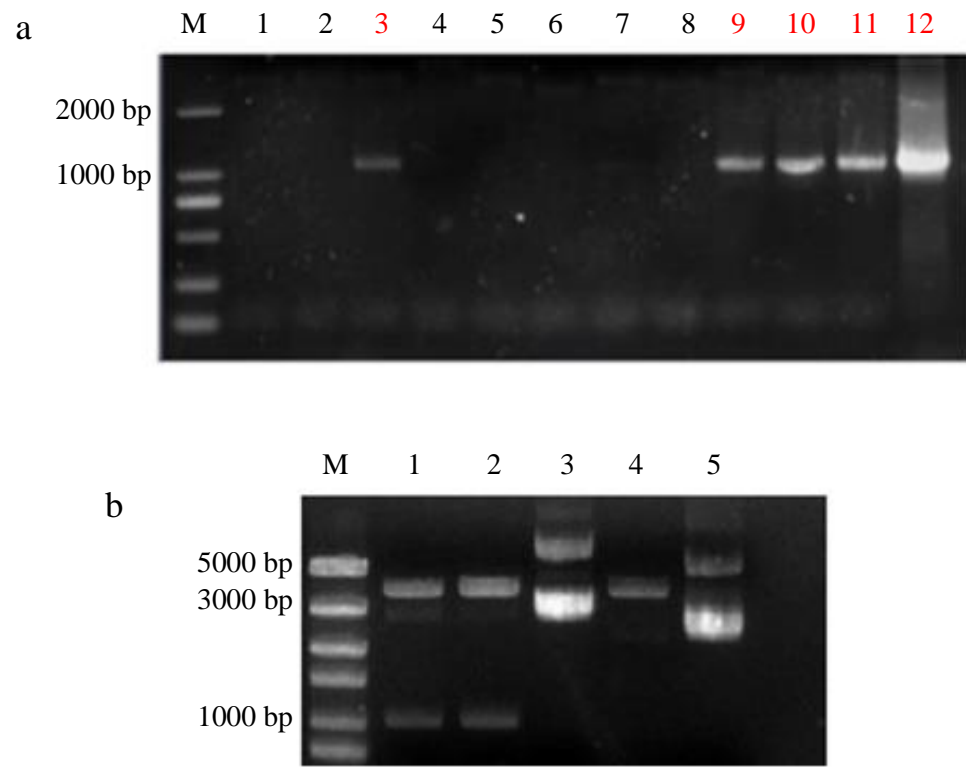

Fig. 6: Transformatnt verification of plasmid pUG:: hptII. a. PCR identification of pUG::hptII (M: 2000bp DNA maker; 1-11: PCR result of the transformants; 12: positive control); b. Double enzyme digestion identification of pUG::hptII (M: 5000bp DNA maker; 1-2: Nco I/Cla I digestion of plasmid pUG::hptII; 3: Nco I/Cla I digestion of plasmid pUG::hyg; 4: Nco I/Cla I digestion of pUG6; 5: Plasmid pUG6)

In order to further determine whether the eykl gene was knocked out, the genomic DNA of the transformants was extracted for PCR verification. The genome DNA of each transformants as well as positive controls (Y-22, YE4-2) were extracted and diluted to the same concentration as template and eyk-F/R designed according to eykl gene flanks were used as primers. As shown in Fig. 7b, the lanes 1-2 are $Y$. lipolytica Y-22 and YE4-2 respectively and the lanes 3-6 were transformants. The results showed that the eykl gene fragment could be amplified from all of the strains. However, the brightness of stripe in lane 5 is $50 \%$ lighter compared with the strips of untransformed $Y$. lipolytica or other transformants. When the DNA of each sample was diluted again to the same concentration as templates, the same PCR result was obtained. Since the presence of single and diploid generation in $Y$. lipolytica, it is speculated that one allele in the diploid strain was knocked out, which led to the phenomenon. Therefore, the No. 5 transformant (YE4-2-5) was subjected to a subsequent shake flask fermentation test. 

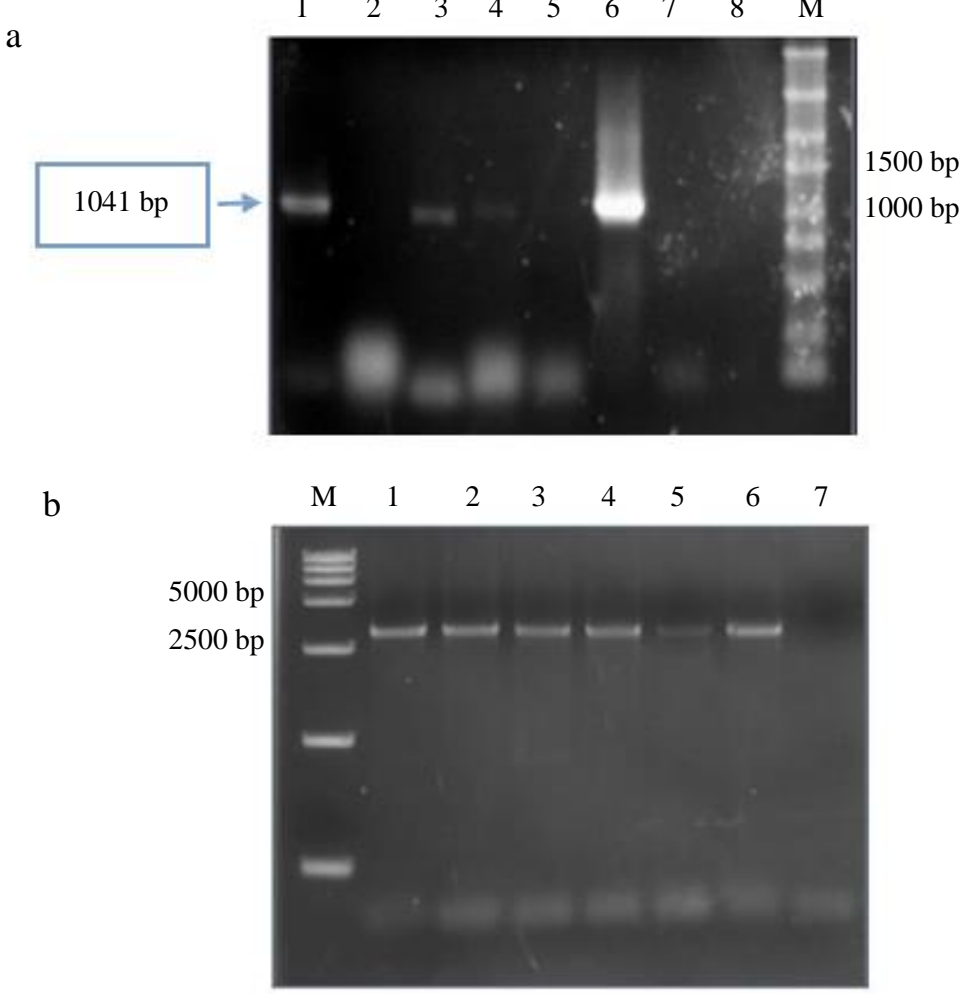

Fig. 7: Screening of eyk1 deleted transformants. a. Sub-PCR identification of transformants transferred with the knockdown

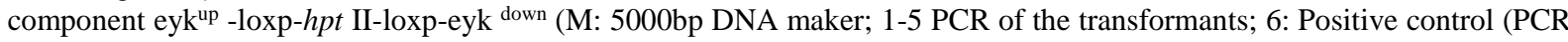
of pUG6::hptII); 7: PCR of Y. lipolytica YE4-2; 8: Negtive control); b. Identification of inverter PCR (M: 5000bp marker; 1: PCR identification of Y-22 genome DNA; 2: PCR identification of YE4-2 genome DNA; 3-6: PCR identification of the transformants genome DNA; 7: Negative control)

Table 5: Fermentation of the recombinant strains

\begin{tabular}{lllll}
\hline Strain & Glucose utilization $(\%)$ & Conversion rate $(\%)$ & Yeild $(\mathrm{g} / \mathrm{L})$ & Productivity $(\mathrm{g} / \mathrm{L} / \mathrm{h})$ \\
\hline YE4-2 & $54.20 \pm 2.18$ & $32.50 \pm 2.62$ & $58.3 \pm 1.09$ & $0.61 \pm 0.08$ \\
YE4-2-5 & $65.02 \pm 4.36$ & $48.51 \pm 1.25$ & $94.6 \pm 3.78$ & $0.99 \pm 0.26$ \\
Increased & $19.96 \pm 1.33 \%$ & $49.26 \pm 1.67 \%$ & $62.26 \pm 1.72 \%$ & $62.26 \pm 2.35 \%$ \\
\hline
\end{tabular}

The Productivity of Erythritol in the Recombinant Strain Y. lipolytica YE4-2-5 was Significantly Improved

The fermentation was carried out in the shake flask with $30 \%$ glucose as substrate and after $96 \mathrm{~h}$ of fermentation, cultures were collected for analysis. Results showed that the average conversion rate ( $\left.\mathrm{Y}_{\text {erythrito//glucose }}\right)$ of the starting strain YE4-2 was 0.325 and the average conversion rate of the recombinant strain No. 5 was $48.51 \%$, which was $49.26 \%$ higher than that of YE4-2 (Table 5). The t-test results showed that the significance reached $5 \%$.

In the past, erythritol productivity in $Y$. lipolytica has largely been improved by classical approaches that consisted of optimizing either the culture medium or culturing conditions (Mirończuk et al., 2014; Rymowicz et al., 2008; Yang et al., 2014). Recently, however, (Mirończuk et al., 2016) found that overexpression of glycerol kinase and glycerol dehydrogenase encoding genes (gutl and gut2) significantly increased the productivity of erythritol of $Y$. lipolytica A101. Compared with the wild-type yeast, overexpression of gutl alone increased the erythritol yield by $23 \%$, while overexpression of gutl and gut 2 together increased the yield by $35 \%$, however, overexpression of gut 2 alone led to a $28 \%$ decrease of the erythritol yield. Carly et al. (2017) overexpressed gutl (glycerol kinase), gut2 (glycerol dehydrogenase), yid A (Erythrose-4PPhosphatatase), tkll (transketolase), alr (erythrose reductase) in $Y$. lipolytica, which aimed to increase the flow of carbon from glycerol to erythritol. The results of fermentation with glycerol as substrate showed that the overexpression of gutl and gut 2 lead to similar results to that of (Mirończuk et al., 2016); while overexpressing tkll-gutl, the yield of erythritol 
was increased by $42 \%$; however, overexpression of $\mathrm{alr}$, yid $A$ reduces the yield of erythritol. They also disrupted eykl gene which involves in the erythritol catabolism based on the tkll-gutl mutant strain and finally resulted in a $75 \%$ increase of the erythritol productivity. Our study also showed that one allae of eykl knock out could significantly increase the erythritol productivity which further proved that eykl gene is crucial on erythritol metabolism pathway; This laid a foundation for subsequent transformation and multiple allele knockout engineering.

Current biotechnological production of erythritol, take a highly concentrated glucose (typically $40 \%$ (w/v)) solution as substrate. These processes reach $40 \%(\mathrm{w} / \mathrm{w})$ conversion rate of D-glucose to erythritol (Moon et al., 2010; Jovanović et al., 2014). In our study, the conversion rate of glucose to erythritol could reach $48.51 \pm 1.25 \%$, which is greatly improved.

\section{Conclusion}

This study reported the establishment of genetic transformation system for the industrialized $Y$. lipolytica mutant YE4-2 and Cre/loxp homologous recombination knockout system containing the selective marker was constructed according to the strain's antibiotic sensitivity. After the recombination of the knock out component eyk ${ }^{\text {up }-l o x p-h p t ~ I I-l o x p-e y k ~}{ }^{\text {down }}$ with $Y$. lipolytica YE4-2 genome DNA, the results show that the resistance gene has entered the yeast genome. While according to the PCR verification of eykl gene, the brightness of the transformant eykl band was about half of that in untransformed $Y$. lipolytica YE4-2 at the same DNA template concentration. Due to the presence of haploid and diploid in $Y$. lipolytica, it was preliminarily determined that one allele of eykl in this recombinant strain was knocked out. The conversion rate of the recombinant strain from glucose to erythritol was significantly (5\% significant by $\mathrm{T}$ test) improved from 32.50 to $48.51 \%$, which was $49.26 \%$ higher than the average conversion rate of YE4-2 and the erythritol productivity is increased by $62.26 \%$. Our study show that one allae of eykl knock out could significantly increase the erythritol productivity which further proved that eykl gene is crucial on erythritol metabolism pathway; This laid a foundation for subsequent transformation and multiple allele knockout engineering.

\section{Acknowledgement}

The authors are grateful to the funding support by Shandong key research and development program-Major scientific and technological projects, China (2019JZZY011005), Chongqing technological innovation and application development key projects (cstc2019jscx-gksbX0113), China Postdoctoral Science
Foundation, China (2019M662362), Innovation Project Special Fund for Post Doctors of Shandong Province, China (201902048). China Postdoctoral Science Foundation (2019M650167).

\section{Author's Contributions}

Xinhe Zhao: Participated in the whole experiment process and also contributed to the interpretation of the results and manuscript preparation.

Tianlong Huang, Yaxin Zhang and Xiaojie Ren: Participated in part of the experimental design.

Yuanda Song: Ameliorated the manuscript.

Bei Guo: Contributed to the guidance of experimental design and ameliorated the manuscript.

\section{Ethics}

This article is original and contains unpublished material. The corresponding author confirms that all of the other authors have read and approved the manuscript and no ethical issues involved.

\section{References}

Amelina, H., Moiseeva, V., Collopy, L. C., Pearson, S. R., Armstrong, C. A., \& Tomita, K. (2016). Sequential and counter-selectable cassettes for fission yeast. BMC biotechnology, 16(1), 76.

Bernt, W. O., Borzelleca, J. F., Flamm, G., \& Munro, I. C. (1996). Erythritol: a review of biological and toxicological studies. Regulatory Toxicology and Pharmacology, 24(2), S191-S197.

Carly, F., Vandermies, M., Telek, S., Steels, S., Thomas, S., Nicaud, J. M., \& Fickers, P. (2017). Enhancing erythritol productivity in Yarrowia lipolytica using metabolic engineering. Metabolic engineering, 42, 19-24.

Chen, X. Z., Rao, Z. M., Shen, W., FANG, H. Y., WANG, Z. X., \& ZHUGE, J. (2008). A Transformation System for Candida glycerinogenes, Based on Zeocin Resistance. Acta Laser Biology Sinica, 17(2), 176.

Dolinski, K., Muir, S., Cardenas, M., \& Heitman, J. (1997). All cyclophilins and FK506 binding proteins are, individually and collectively, dispensable for viability in Saccharomyces cerevisiae. Proceedings of the National Academy of Sciences, 94(24), 13093-13098.

Dou, W. F., Gao, H., Zhang, D., Zhang, L., Xu, Z., \& Lu, M. (2013). Breeding of Torula sp. B84512 haploid and analysis of erythritol production characteristics. Journal of Food Science and Biotechnology 32, 1673-1689. 
Falciatore, A., Casotti, R., Leblanc, C., Abrescia, C., \& Bowler, C. (1999). Transformation of nonselectable reporter genes in marine diatoms. Marine Biotechnology, 1(3), 239-251.

Fickers, P., Le Dall, M. T., Gaillardin, C., Thonart, P., \& Nicaud, J. M. (2003). New disruption cassettes for rapid gene disruption and marker rescue in the yeast Yarrowia lipolytica. Journal of microbiological methods, 55(3), 727-737.

$\mathrm{Fu}$, J. (2013). The modification of Cre/Loxp recombination system and the application in Scheffersomyces stipitis, (Doctoral Thesis), Jiang nan University, China.

Fraczek, M. G., Naseeb, S., \& Delneri, D. (2018). History of genome editing in yeast. Yeast, 35(5), 361-368.

Germec, M., Turhan, I., Karhan, M., \& Demirci, A. (2019). Kinetic modeling and techno-economic feasibility of ethanol production from carob extract based medium in biofilm reactor. Applied Sciences, 9(10), 2121.

Han, L., Guo, B., Zhang, X., \& Pei, J. (2015). Metabolizing enzymes and mitochondrial DNA variation of a high yield erythritol producing Yarrowia lipolytica mutant. Food and Fermentation Industries, 41, 52-56.

Hirschman, J. E., Balakrishnan, R., Christie, K. R., Costanzo, M. C., Dwight, S. S., Engel, S. R., ... \& Park, J. (2006). Genome Snapshot: a new resource at the Saccharomyces Genome Database (SGD) presenting an overview of the Saccharomyces cerevisiae genome. Nucleic acids research, 34(suppl_1), D442-D445.

Jovanović, B., Mach, R. L., \& Mach-Aigner, A. R. (2014). Erythritol production on wheat straw using Trichoderma reesei. AMB Express, 4(1), 1-12.

Kawanabe, J., Hirasawa, M., Takeuchi, T., Oda, T., \& Ikeda, T. (1992). Noncariogenicity of erythritol as a substrate. Caries Research, 26(5), 358-362.

Kimoto, H., \& Taketo, A. (2003). Efficient electrotransformation system and gene targeting in pyogenic streptococci. Bioscience, biotechnology and biochemistry, 67(10), 2203-2209.

Kimoto, H., \& Taketo, A. (1997). Initial stage of DNAelectrotransfer into E. coli cells. The Journal of Biochemistry, 122(1), 237-242.

Lee, J. K., Koo, B. S., \& Kim, S. Y. (2002). Fumaratemediated inhibition of erythrose reductase, a key enzyme for erythritol production by Torula corallina. Applied and Environmental Microbiology, 68(9), 4534-4538.

Mirończuk, A. M., Furgała, J., Rakicka, M., \& Rymowicz, W. (2014). Enhanced production of erythritol by Yarrowia lipolytica on glycerol in repeated batch cultures. Journal of industrial microbiology \& biotechnology, 41(1), 57-64.
Mirończuk, A. M., Rzechonek, D. A., Biegalska, A., Rakicka, M., \& Dobrowolski, A. (2016). A novel strain of Yarrowia lipolytica as a platform for valueadded product synthesis from glycerol. Biotechnology for Biofuels, 9(1), 180.

Moon, H. J., Jeya, M., Kim, I. W., \& Lee, J. K. (2010). Biotechnological production of erythritol and its applications. Applied microbiology and biotechnology, 86(4), 1017-1025.

Papanikolaou, S., Chevalot, I., Komaitis, M., Marc, I., \& Aggelis, G. (2002). Single cell oil production by Yarrowia lipolytica growing on an industrial derivative of animal fat in batch cultures. Applied Microbiology and Biotechnology, 58(3), 308-312.

Pei, J., Huang, L., Zhang, L., \& Shubin, T. (2015). Erythritol production with Yarrowia lipolitica. Food and Fermentation Industries, 41, 28-33.

Rymowicz, W., Rywińska, A., \& Gładkowski, W. (2008). Simultaneous production of citric acid and erythritol from crude glycerol by Yarrowia lipolytica Wratislavia K1. Chemical Papers, 62(3), 239.

Rymowicz, W., Rywińska, A., \& Marcinkiewicz, M. (2009). High-yield production of erythritol from raw glycerol in fed-batch cultures of Yarrowia lipolytica. Biotechnology Letters, 31(3), 377-380.

Saito, Y., Taguchi, H., \& Akamatsu, T. (2006). Fate of transforming bacterial genome following incorporation into competent cells of Bacillus subtilis: a continuous length of incorporated DNA. Journal of bioscience and bioengineering, 101(3), 257-262.

Twaruschek, K., Spörhase, P., Michlmayr, H., Wiesenberger, G., \& Adam, G. (2018). New plasmids for Fusarium transformation allowing positive-negative selection and efficient Cre-loxP mediated marker recycling. Frontiers in microbiology, 9, 1954.

Vandermies, M., Denies, O., Nicaud, J. M., \& Fickers, P. (2017). eykl encoding erythrulose kinase as a catabolic selectable marker for genome editing in the non-conventional yeast Yarrowia lipolytica. Journal of Microbiological Methods, 139, 161-164.

Vickers, C. E., Bydder, S. F., Zhou, Y., \& Nielsen, L. K. (2013). Dual gene expression cassette vectors with antibiotic selection markers for engineering in Saccharomyces cerevisiae. Microbial cell factories, 12(1), 96.

Wei, S., Liu, Y., Wu, M., Ma, T., Bai, X., Hou, J., ... \& Bao, X. (2018). Disruption of the transcription factors Thi2p and Nrm1p alleviates the post-glucose effect on xylose utilization in Saccharomyces e. Biotechnology for biofuels, 11(1), 112.

Yang, L. B., Zhan, X. B., Zheng, Z. Y., Wu, J. R., Gao, M. J., \& Lin, C. C. (2014). A novel osmotic pressure control fed-batch fermentation strategy for improvement of erythritol production by Yarrowia lipolytica from glycerol. Bioresource technology, $151,120-127$. 


\section{Appendix}

\section{Primer list}

\begin{tabular}{|c|c|c|}
\hline Primers & Primer sequences $\left(5^{\prime}-3^{\prime}\right)$ & Purpose and description \\
\hline$p p z-\mathrm{F} 2$ & GCTCTAGAGCGTGAGACCTTCGTTTGTGCG $(x b a$ I) & Amplify $p p z$ fragment \\
\hline ppz-R2 & GAAGATCTTCTTTCGGTTAGAGCGGATGTG ( $B g l$ II) & Amplify $p p z$ fragment \\
\hline eykl-PF & GTTGTGTGATGAGACCTTGGTGC & Amplify eykl fragment \\
\hline eyk-TR & GTTTAGGTGCCTGAAGACGGTG & Amplify eykl fragment \\
\hline zeo-F & CAATCTAATCTAAGGGGCGGTGT & Zeocin resistance identification \\
\hline zeo-R & GGGAGGGCGTGAATGTAAGC & Zeocin resistance identification \\
\hline EL-F & $\begin{array}{l}\text { CTTCTATAAGAAGCTCCTTTCCCCACAATTGGCCCACAC } \\
\text { GACACTTCTACACACTTACACaacgcggecgecagctgaag }\end{array}$ & pUG6 disruption cassettes amplication primer \\
\hline EL-R & $\begin{array}{l}\text { GTTCCATCATAAATATCATTAAAAATTATATGCCATTTACA } \\
\text { AGTGCTCGTACAAGTACTCctatagggagaccggcagat }\end{array}$ & pUG6 disruption cassettes amplication primer \\
\hline$h p t-\mathrm{F}$ & CATGCCATGGCATGTATGAAAAAGCCTGAACT ( Nco I) & Hygromycin B resistant gene primer \\
\hline$h p t-\mathrm{R}$ & CCATCGATGGCGGTCGGCATCTACTCTATT ( $\mathrm{Cla}$ I) & Hygromycin B resistant gene primer \\
\hline eyk $^{\mathrm{up}}-\mathrm{F}$ & TATCGGCAACCTTAGCGGCA & $\mathrm{P}$ fragment primer \\
\hline eyk ${ }^{\mathrm{up}}-\mathrm{R}$ & AAAGGCCATTTAGGCCTGTAGAAGTGTCGTGTGGGC & $\mathrm{P}$ fragment primer $(s f i \mathrm{I})$ \\
\hline eyk $^{\text {down_F }}$ & TATGGCCTTGATGGCCGAGAAGCGAAGGAATATGAG $(s f i$ I) & $\mathrm{T}$ fragment $(s f i \mathrm{I})$ \\
\hline eyk $^{\text {down }}-\mathrm{R}$ & TTAGGTGCCTGAAGACGGTG & $\mathrm{T}$ fragment \\
\hline
\end{tabular}

